\title{
DIREITOS HUMANOS, PROPRIEDADE PRIVADA E EDUCAÇÃO
}

\author{
Reginaldo Carmello Corrêa de MORAES*
}

\begin{abstract}
RESUMO: O presente texto constitui sintese de comunicação do autor à III Conferência Brasileira de Educação (Niterói, outubro de 1984). Afirma-se a necessidade de discutir as raizes da idéia de direitos do individuo e seu vínculo, no pensamento fundador de Locke, com a propriedade e, mais ainda, a liberdade e autonomia da pessoa humana. Discute-se ainda o suposto liberal-racionalista de alocação ótima dos recursos sociais através do choque e combinação de interesses privados. Uma dupla crise de nossos tempos: crise da concepção de universo auto-regulado laplaceano (e sua ciência: o determinismo mecânico ou substancial) e a crise da crença na alocação ótima via mercado. $A$ idéia de intervenção do Estado na economia não significa a destruição da propriedade privada, da lei do valor e do lucro. Apenas atesta a sua sobrevivência e procura garantir seu desenvolvimento. Não se pode pensar analogamente a idéia de educação como direito social garantido e alocado pelo Estado, como investimento no "capital humano"'? Qual o sentido da expressão - uma "política educacional"?

UNITERMOS: Ideologia; educação; propriedade privada; organização do saber; capital humano; divisão do trabalho.
\end{abstract}

$$
-\mathrm{I} \text { - }
$$

Entre os “direitos inalienáveis da pessoa humana”, inalienáveis exatamente por constituírem parte da natureza humana, Locke arrolava o direito à propriedade. De fato, os direitos remetiam-se reciprocamente e o seu sistema era habitado por uma solidariedade fundada nas idéias de lei natural e Razão.

O direito à propriedade é, nesse pensamento, o verso de outro direito, configurado na idéia de liberdade e autonomia da pessoa humana. Liberdade inalienável: a lei natural, a Razão, não concebe a escravidão ou qualquer forma de alienação do próprio corpo e da própria vontade.

A propriedade das coisas do mundo irá derivar dessa primeira propriedade:

“Embora a terra e todas as criaturas inferiores sejam comuns a todos os homens, cada homem tem uma propriedade em sua própria pessoa (...) O trabalho de seu corpo e a obra de suas mãos, pode-se dizer, são propriedade dele', (3, § 27).

Mas ocorre que a "condição da vida humana (...) exige trabalho e material com que trabalhar' - o homem se objetiva, ele verte o seu suor e seu sangue na terra, deposita sobre as coisas do mundo o seu corpo/obra/trabalho, de modo tal que nessas coisas do mundo, em seguida, está infiltrado o indivíduo e a propriedade de si mesmo. A “condição da vida humana (...) necessariamente introduziu a propriedade" ( $1, \S$ 35). Quando se apropria dos pedaços do mundo que trabalha e transforma, é de si mesmo que o indivíduo toma posse: "A extensão de terra que um homem lavra, planta,

\footnotetext{
* Departamento de Ciências Sociais Aplicadas a Educação - Faculdade de Educação - UNICAMP - I3100 - Campinas - S P.
} 
MORAES, R.C.C. de - Direitos humanos, propriedade privada e educação. Trans/Form/Ação, São Paulo, 8:25-28, 1985 .

melhora, cultiva, cujos produtos usa, constitui a sua propriedade. Pelo trabalho, por assim dizer, separa-a do comum', $(3, \S 35)$.

Estanquemos neste instante a nossa reflexão para sublinhar cuidadosamente que aí está um dos "mitos fundadores" do capital como acumulação originária proveniente da renúncia ao ócio e ao prazer, como fruto do "suor do rosto". Mais do que isso, Locke assegura o sentido "progressista" da propriedade privada: não se trata apenas de uma apropriação que interessa ao indivíduo, mas ao homem enquanto gênero. "Aquele que toma posse da terra pelo trabalho não diminui mas aumenta as reservas comuns da humanidade' ( $3, \S 37)$ - dirá o inglês, antecipando-se a Quesnay, de La Rivière, Smith, na afirmação do caráter positivo, para o avanço da civilização, das desigualdades de riqueza.

Peço ao leitor que retenha a lógica desse argumento que aqui sintetizamos. Que retenha o vínculo estabelecido entre liberdade-indivíduo-trabalho-propriedade. Nós vamos reencontrá-lo mais adiante em nossa reflexão.

- II -

A confiança "lógica" na melhoria das condições da vida humana através e no interior dos interesses individuais conflitantes, essa convicção otimista reaparece, no século seguinte ao de Locke, na extraordinária obra de Adam Smith. Seu argumento a respeito da divisão do trabalho e da produtividade (6, livro I, cap. 1 ) é, nesse sentido, fundamental e pode ser resumido do seguinte modo:

1. A divisão do trabalho aumenta a destreza e a rapidez do trabalhador na sua operação específica;

2. ela diminui, por outro lado, a porosidade entre as operações e a dispersão do trabalhador no intervalo das mudanças, aumentando a disciplina dos corpos e mentes;

3. simplifica o trabalho de inventar máquinas, uma vez que estas se destinam a operações cada vez mais simples.

Ora, a razão e a linguagem, naturais ao homem, implicam a troca (de bens de razão, pelo discurso, ou de bens materiais) (6, livro I, cap. 4). A troca, por sua vez, implica e supõe a divisão do trabalho e a busca do interesse pessoal (6, livro I, cap. 2). A divisão do trabalho favorece o incremento da produtividade, como pudemos notar, e, portanto, a realização de benefícios coletivos. Assim, no indivíduo e na sua egoísta procura de vantagens, está radicada, embrionariamente, a realização do bem comum. A “mão invisível"' (6, livro IV, cap. 2) do mercado, da lei do valor, acondiciona, cuidadosamente, cada átomo no conjunto simultaneamente dinâmico e equilibrado, autoajustado, da sociedade humana.

Não apenas a propriedade privada e uma forma histórica de organização da produção material são dados como "naturais" à vida humana. O mundo fragmentado dos homens, seus ofícios e saberes, é unificado pelo fato mesmo da atomização de interesses.

Estabelece-se a conciliação entre autonomia e liberdade individual e, de outro lado, a ordem do mundo, sua finalidade ótima. Antes que problema, a autonomia é condição para a existência da ordem e do finalismo. Essa imagem da história encontrará sua correspondente metafísica na filosofia kantiana, onde o plano da natureza, o universo concertado, não contradiz, mas supõe a autonomia e os conflitos dos interesses individuais/grupais. 
MORAES, R.C.C. de - Direitos humanos, propriedade privada e educação. Trans/Form/Ação, São Paulo, 8:25-28, 1985.

\section{- III -}

Façamos uma pausa nesta reconstituição de alguns episódios da história das idéias modernas. Uma pausa para repetir e sintetizar, para insistir e condensar. Se autonomia e finalismo não se contradizem, mas se produzem reciprocamente, qual a política adequada ao mundo dos saberes e ofícios? Ao que tudo indica, uma política do negativo: tratar-se-ia de eliminar os antinaturais obstáculos ao desenvolvimento do indivíduo. A garantia dos direitos individuais ao "progresso" está indissoluvelmente ligada à consecução de objetivos comuns da humanidade enquanto espécie.

Contudo, os séculos XIX e XX assistiram à crise de duas utopias. Em primeiro lugar, da utopia de um mundo sócio-econômico auto-regulado em função (em direção) do ótimo - as teorias de planificação conservadoras ou libertárias, a exigir estabelecimentos de valores ou metas previamente deliberadas. Em segundo lugar, crise da utopia de um mundo natural auto-regulado, absolutamente determinado e, portanto, potencialmente presente a um Divino Calculador - em suma, a crise do universo laplaceano.

Deixemos de lado esta última, que pelo momento não nos interessa diretamente. A crise do pensamento liberal deixará à deriva grande parte das teorias políticas. Pode-se dizer que a resistência à revisão alcança seu limite e superação após as crises dos anos 20, com a emergência da revolução keynesiana. A intervenção do Estado não significará eliminação do mercado, "revogação" da lei do valor, da propriedade privada e do lucro. Na verdade, ela apenas atesta e conserva sua existência.

Pois então restará pensar essa intervenção no plano educacional - o plano dos saberes e ofícios. Não se trata mais de apostar na educação como direito social do indivíduo, que, uma vez garantido, propiciará, pelo mundo da competição, o progresso de todos. Agora, trata-se de pensar a educação como dever e investimento do Estado, uma intervenção que pode eventualmente contradizer impulsos individuais.

A utopia smithiana de harmonização de saberes e fazeres através da mão-invisível é substituída então por um modelo que se assemelha a outra utopia, aquela sugerida por Bacon, na Nova Atlântida (2): não é a sociedade, pela própria força natural dos interesses, que assegura a felicidade e o bem-estar coletivo. O Estado e sua cuidadosa organização das ciências e técnicas modelam a sociedade e propiciam a felicidade planejada.

Mas ainda nesta intervenção - como na revolução keynesiana - os pressupostos liberais e individualistas não são questionados, mas emendados.

\section{- IV -}

É interessante notar como Marx, nos Grundrisse, examina a imagem adquirida pelo trabalhador no capitalismo: o trabalho como capital do operário, a família operária como loja e fábrica de força de trabalho. Tive ocasião de discutir essa questão em outras oportunidades (4 e 5). Nos mesmos textos, procurei expôr como a caracterização de Francisco de Oliveira - a família operária como “agente que acumula ativos" — é uma descrição que não se distancia daquela operada pela chamada "contabilidade social"' (não-marxista).

O mais curioso, no entanto, seria analisar como esses elementos constituem pensamento (e prática) nas chamadas “teorias do capital humano". Essa passagem - sugerida por um trabalho de J. Arapiraca (1) sobre a USAID e a educação brasileira - seria ainda mais chocante se lembrarmos de certo marxismo que, em 1935, chamava o homem "de o capital mais precioso". 
MORAES, R.C.C. de - Direitos humanos, propriedade privada e educação. Trans/Form/Ação, São Paulo, 8:25-28, 1985.

Arapiraca sintetiza os elementos da teoria do capital humano de uma forma que nos convém ler, ainda que rapidamente e como ponto de partida. O autor afirma que, para essa concepção, o "capital humano é algo de deliberadamente produzido pelos investimentos que se faz no indivíduo a partir da educação formal e do treinamento; que a produtividade do indivíduo resulta na maior ou menor quantidade de capital humano que este venha a possuir', (1, p. 41). Ela sustenta ainda os seguintes argumentos:

$1 .^{\circ}$ ) Os fatores de produção são remunerados conforme sua produtividade marginal - e o fator trabalho é um deles (conforme o suposto neoclássico);

$2 .^{\circ}$ ) a educação aumenta a produtividade do fator trabalho;

$3 .^{\circ}$ ) a educação aumenta a renda do fator trabalho;

$4 .^{\circ}$ ) as pessoas são bens como potencialidades produtivas e, portanto, as habilidades humanas são bens de produção produzidos, isto é, capital;

$5 .^{\circ}$ ) a educação é investimento básico no capital humano.

Este rápido alinhamento da história de uma perspectiva - e de suas adequações aos tempos mutantes - parece-me um passo inicial necessário para imaginar e pensar o que seria uma concepção de educação que não partisse dos pressupostos gerados por uma ideologia datada e ref erida à classe que criou os nossos tempos e o nosso modo de ver e viver o mundo. Estou seguro de que apenas sugiro temas e levanto problemas, mas acredito que vê-los como problemas é uma necessidade inarredável. Isso posto, como diria Leibniz, “calculemos".

MORAES, R.C.C. de - Human rights, private property and education. Trans/Form/Ação, São PauIo, 8:25-28, 1985.

ABSTR ACT: The present text constitutes a summary of a talk given by the author at the III Conferência Brasileira de Educação (Niterói, October 1984). It is here claimed that there is a need to discuss the roots of the idea of rights of the individual and of its link, in Locke's founding thought, with property and, moreover, with the freedom and autonomy of the human person. Furthermore, a discussion is made of the liberal-rationalist assumption of the optimum allocation of social resources through the clash and combination of private interests. A twofold crisis of our times: crisis of the view of a self-regulated Laplacean universe (and its science: the mechanical or substancial determinism) and the crisis of the belief in the optimum allocation via market. The idea of the intervention of the State in the economy does not mean a destruction of private property nor of the value law and of profit. It only attests to its survival and seeks to ensure it implementation. Can't the idea of education be analogously thought of as a social right guaranteed and allocated by the State; as an investment in "human capital"? What is the meaning of the expression "educational policy'?

KEY-WORDS: Ideology; education; private property; organization of knowledge; human capital; divison of labour.

\section{REFERÊNCIAS BIBLIOGRÁFICAS}

1. ARAPIRACA, J. O. A USAID e a educação brasileira. S. Paulo, Cortez Ed., 1983.

2. BACON, F. - Nova Atlântica. S. Paulo, Abril, 1979.

3. LOCKE, J. - Segundo tratado sobre o governo. S. Paulo, Abril, 1978.

4. MORAES, R.C.C. de - Marx, o cínico? Trans/Form/Ação, 6: 37-43, 1983.
5. MORAES, R.C.C. de - A Fênix Tropical - nota crítica sobre o dualismo e a teoria da dependência. Araraquara, ILCSE-UNESP, 1984. (mimeo).

6. SMITH, A. - A Riqueza das Nações. S. Paulo, Abril, 1983. Livro I, cap. 4. 